Annals of Glaciology 141990

$\odot$ International Glaciological Society

\title{
RECENT WARMING IN CENTRAL GREENLAND?
}

\author{
by \\ Richard B. Alley \\ (Earth System Science Center and Department of Geosciences, The Pennsylvania State University, \\ University Park, PA 16802, U.S.A.) \\ and \\ Bruce R, Koci
}

(Polar Ice Coring Office, University of Alaska Fairbanks, Fairbanks, AK 99775, U.S.A.)

\section{ABSTRACT}

Recent warming has occurred in near-surface firn in central Greenland, as shown by analysis of a $217 \mathrm{~m}$ temperature profile from the GISP2 site. However, this warming falls within the range of natural variability and provides no clear evidence of a greenhouse signal.

\section{INTRODUCTION}

Records of surface temperatures in sites far from local anthropogenic influences are useful for determining natural climatic variability and for detecting regional or global anthropogenic influences. One goal of ice-core research is to learn paleotemperatures over land ice. Here we report temperature data from the Greenland Ice Sheet Project 2 (GISP2) site near the summit of the Greenland ice sheet, and we derive a history of surface-snow temperatures that explains most of the variance of the data.

\section{METHODS}

The first hole drilled at the GISP2 site $\left(72^{\circ} \mathrm{N}, 38^{\circ} \mathrm{W}\right.$, 3200 m a.s.1.; measured by D. Roberts: personal communication from J.F. Bolzan, 1989) during summer, 1989 reached a depth of $217 \mathrm{~m}$ (the $100 \mathrm{~mm}$ diameter core recovered is being analyzed primarily by $\mathrm{Dr}$ E. Mosley-Thompson, Ohio State University). Following drilling, temperatures were measured in this hole by raising and lowering a single thermistor (factory three-point calibrated; accurate to $\pm 0.1^{\circ} \mathrm{C}$ or better) on a single cable. This technique minimizes the thermal disturbance of the hole by the measuring apparatus. Repeated profiles were measured at times up to $25 \mathrm{~d}$ after completion of drilling. For the later profiles, all points deeper than $15 \mathrm{~m}$ were reproducible to $\pm 0.01^{\circ} \mathrm{C}$. (This reproducibility required that measurements in the top $20 \mathrm{~m}$ be taken on relatively calm days.) A second thermistor showed a consistent offset of about $0.035^{\circ} \mathrm{C}$, but reproduced the measured trend within $\pm 0.01^{\circ} \mathrm{C}$. Data are plotted in Figure 1a. Temperature gradients along the hole are sufficiently small $\left(\leqslant 0.004^{\circ} \mathrm{C} \mathrm{m}^{-1}\right)$ that the presence of the hole will not cause convective or conductive (Sanderson, 1977) fluxes large enough to perturb the profile significantly.

To determine the history of surface temperatures, we used available data to constrain the timing of likely climatic events as closely as possible, and applied this history as the surface boundary condition for a time-dependent model of firn and ice temperatures. We then adjusted the magnitudes of events to minimize the deviation between model and observed profiles, and adjusted the timing of events as needed to further minimize deviations (see summary in Table I).

TABLE I FREE AND CONSTRAINED PARAMETERS USED IN MODEL

Parameter

Treatment

Ice temperature

Thermal properties

Vertical strain- rate

Accumulation rate

Depth-density profile

Initial temperature

Grid basal temperature

Surface temperature which allows for the temperature and density dependence of thermal properties and for the small but significant heat generation by firn densification. We added the term for heat generation from ice deformation assuming constant vertical strain-rate and two-dimensional flow (Paterson, 1981 , p. 191); this term is insignificant at the depths considered by Johnsen (1977) but affects results towards the bottom of our model grid. The GISP2 site is only about $30 \mathrm{~km}$ west of the ice crest and about $30 \mathrm{~m}$ lower (Hodge and others, in press), and has a balance velocity of $2-3 \mathrm{~m} \mathrm{a}^{-1}$. Ice at the bottom of the bore hole originated only about $2 \mathrm{~km}$ east and $2 \mathrm{~m}$ higher than the top of the bore hole (ignoring any local topography, which appears to be small at the site). Observed lateral variations in snow accumulation and $10 \mathrm{~m}$ temperature in the region appear to be smooth and small $\left(<0.001 \mathrm{~m}\right.$ ice $\mathrm{a}^{-1} \mathrm{~km}^{-1},<0.005^{\circ} \mathrm{C} \mathrm{km}^{-1}$; J.F. Bolzan, in preparation). Variations in accumulation and surface temperature along the flowline thus should be negligible, and are ignored here.

Thermal properties used in the model are from Weller and Schwerdtfeger (1977). We forced the model using a sinusoidal annual cycle of surface temperature with an amplitude of $36^{\circ} \mathrm{C}$ (C. Stearns, private communication, 
1989); as noted by Johnsen (1977), the temperature dependence of thermal properties causes the $10 \mathrm{~m}$ temperature to depend weakly on the amplitude of the annual cycle at the surface. We assumed a steady depthdensity profile at the modern measured value. We also assumed steady accumulation at a rate of $0.242 \mathrm{~m} \mathrm{a}^{-1}$ ice, the average value over the last $300 \mathrm{a}$ at the site, based on the observed depth-density profile and on identification of volcanic marker events in the GISP2 B core drilled about $200 \mathrm{~m}$ from the hole in which temperatures were collected (K. Taylor, private communication, 1989).

Likely climatic events are highlighted by Johnsen (1977), Dahl-Jensen and Johnsen (1986) and other workers. The major events in most northern hemisphere locations include the Little Ice Age $(\approx 1500-1900$ A.D. $)$, warming in the middle of the 20th century, and warming in the 1980s. The needed resolution of this history drops off rapidly with increasing age; a $1{ }^{\circ} \mathrm{C}$ perturbation in surface temperature lasting $1 \mathrm{a}$ is detectable (amplitude $>0.01{ }^{\circ} \mathrm{C}$ ) in the firn for only $25 \mathrm{a}$, whereas a $1{ }^{\circ} \mathrm{C}$ perturbation lasting $10 \mathrm{a}$ is detectable for $300 \mathrm{a}$, and one lasting $100 \mathrm{a}$ is detectable for 900 a. Simulations were begun in 1500 A.D. from a calculated steady profile based on a geothermal flux of $40 \mathrm{~mW} \mathrm{~m}^{-2}$ and a surface temperature that was treated as a free parameter in the model; results were largely independent of the assumed geothermal flux within likely values, but were sensitive to the surface temperature prior to the Little Ice Age. During non-steady simulations we held the temperature constant at the initial value at $600 \mathrm{~m}$ depth, which is deeper than significant penetration of the thermal perturbations modeled.

Season-resolving simulations over $500 \mathrm{a}$ and $600 \mathrm{~m}$ are computer-intensive. To optimize use of computer resources, we chose to control the choice of forward models manually. That is, we first ran a series of simulations for standard perturbations $\left(0.1\right.$ and $1{ }^{\circ} \mathrm{C}$, lasting 1,10 and $\left.100 \mathrm{a}\right)$, and then used these to select the magnitude of temperature perturbations for each simulation. This procedure is faster and more robust than most formal inversions, although it is more dependent on the skill and patience of the operator; historically, it is the technique usually used for the analysis of ice-temperature records.

We found that no steady profile is able to match the observations closely. We then sought the surface-temperature history that minimizes the variance between observed and non-steady model profiles and that yields a fit within $1-2$ standard relative measurement errors $\left(0.01-0.02{ }^{\circ} \mathrm{C}\right)$ everywhere.

\section{RESULTS}

The measured profile in Figure 1a shows fluctuations that appear consistent with a Little Ice Age cooling, a warming to the middle of this century, cooling, and a recent warming. This was confirmed when our first nonsteady simulation based on this history explained $80 \%$ of the variance between the data and the best-fit steady model profile.

Our best-fit surface-temperature history is shown in Figure $1 \mathrm{~b}$, and the resulting temperature-depth curve is shown as a smooth curve over the measured profile plotted in Figure 1a. This model explains $97.5 \%$ of the variance between the data and the best-fit steady model profile, when the data are interpolated to the same spacing as the model grid; the standard deviation between model and observed temperatures is $0.010^{\circ} \mathrm{C}$, and the maximum misfit is $<0.015^{\circ} \mathrm{C}$. (The data point at $15 \mathrm{~m}$ depth is not resolved by the model grid. The seasonal cycle is evident at $15 \mathrm{~m}$ and above, and becomes quite large at shallow depths not plotted.)

If the timing of each point in Figure $\mathrm{lb}$ is held constant, then changing the temperature of any one point by $0.1^{\circ} \mathrm{C}$ (and by only $0.01-0.02 \mathrm{C}$, in most cases) causes a significant increase in the variance between measured and modeled profiles, based on an f-test at the $90 \%$ confidence level. One cannot determine uniquely the surfacetemperature history from an inversion such as this; thus, slightly better fits undoubtedly could be obtained by varying both the timing and magnitude of events, and by adding more points and varying them. In particular, it appears that a
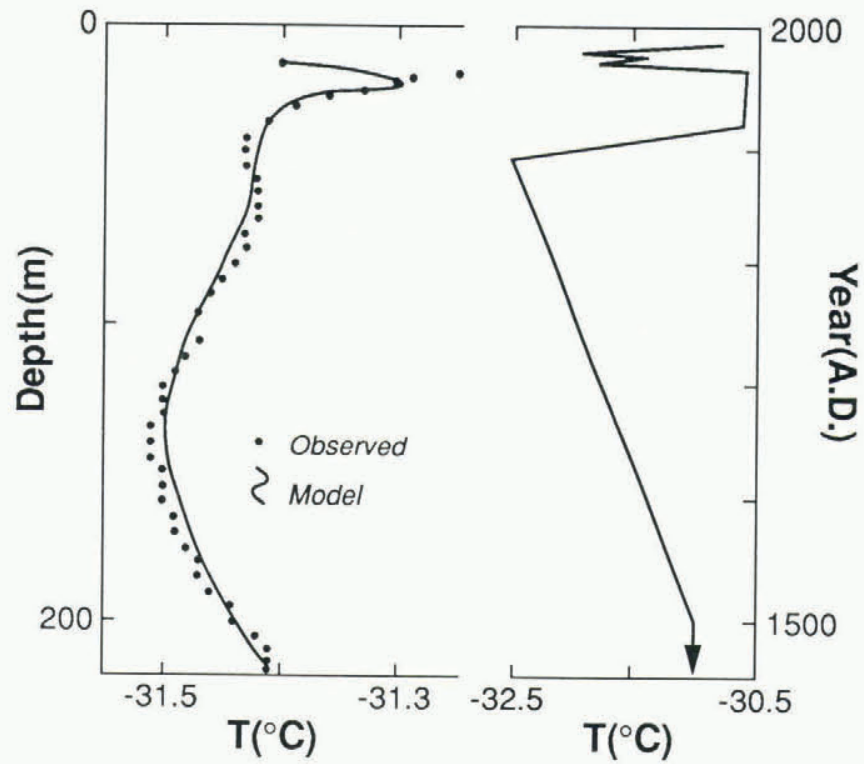

Fig. 1a. Temperature-depth profile, in ${ }^{\circ} \mathrm{C}$. Data (.) measured with first thermistor (second thermistor was consistently $0.035^{\circ} \mathrm{C}$ colder), and model results (smooth curve). Seasonal effects from the two years prior to drilling are evident between 12 and $15 \mathrm{~m}$ : they are large (but not plotted) shallower than $12 \mathrm{~m}$. 1b. Best-fit history of surface temperature.

temperature fluctuations have been somewhat larger and higher in frequency than shown in Figure lb. The goodness of fit obtained here suggests that we are close to the true temperature history, although with certain reservations discussed below.

The model starts with the steady profile for a surface temperature of $-31.01^{\circ} \mathrm{C}$, and Little Ice Age cooling is initiated in 1500 A.D. The average temperature in the best-fit simulation from $1500-1989$ A.D. is $-31.63^{\circ} \mathrm{C}$. Periods hotter or colder than this post-1500 average are listed in Table II, together with the maximum deviation from the average during each period.

\section{DISCUSSION}

The goal of studies such as this is to re-create surface air temperatures. This is hindered for ice-temperature studies by the non-uniqueness of the inversion, but also by the fact that the forcing is the near-surface firn temperature rather than the air temperature. At dry-snow sites such

TABLE II. TIMING AND MAXIMUM CHANGE OF BEST-FIT SIMULATION SURFACE TEMPERATURE FROM BEST-FIT MEAN BETWEEN 1500-1989 A.D. OF $-31.63^{\circ} \mathrm{C}$.
Year (A.D.)
Maximum change $\left({ }^{\circ} \mathrm{C}\right)$

1500-1659

$+0.62$

1659-1905

1905-1969

1969-1972

1972-1978

1978-1982

1982-1989 
as GISP2, the temperature at $10 \mathrm{~m}$ depth typically is within a few tenths of a degree of the mean annual air temperature, with the firn usually colder than the air; however, the difference can be as large as a few degrees (see review in Paterson, 1981; p. 186-191). The reasons for this difference are not understood fully. In re-creating trends of surface air temperature from firn temperatures, we assume that the difference between the two varies more slowly than does the air temperature; this seems likely but is unproven.

The other major method of re-creating surface temperatures on ice sheets is to measure isotopic composition of ice cores. After correction for changes in watervapor source and path and for ice-flow effects, this yields the temperature at the condensation level for snowfall. Again, surface-temperature changes can be inferred from this data set only if the difference between surface and condensation temperature varies more slowly than does the surface temperature.

If condensation temperatures and firn temperatures vary in harmony, then our confidence is improved that both are tracking near-surface temperature. Some workers have tested for parallel trends by using the isotopically derived temperature history as a boundary condition for timedependent models for firn temperature, and determining whether this explained much of the variance in firn temperatures (e.g. Johnsen, 1977). We will conduct this experiment when isotopic data become available from the GISP2 site. However, we feel that confidence is gained if the firn-temperature analysis is first conducted independently from the local isotopic analysis; similar results from isotopic and firn-temperature studies conducted fully independently would be good evidence for past trends in surface temperature.

Pending the completion of isotopic studies, we can draw some tentative conclusions from our analysis. Figure $1 \mathrm{~b}$ and Table II show that warming has occurred recently, but that this warming is not unusual if compared to earlier temperature fluctuations. The magnitude of the natural climatic variability is sufficiently large $\left(\approx 1^{\circ} \mathrm{C}\right)$ that any recent anthropogenic warming (typically suggested to be $\approx 0.1-1^{\circ} \mathrm{C}$ ) would not be clearly recognizable. Our results can be viewed as consistent either with natural climatic variability or with incipient greenhouse warming, dependent on the null hypothesis adopted.

\section{ACKNOWLEDGEMENTS}

We thank the GISP2 Science Management Office, the Polar Ice Coring Office, the 109th Air National Guard, and Drs J. Bolzan, E. Mosley-Thompson, K. Taylor and N. Young for assistance. This research was supported in part by the U.S. National Science Foundation, Division of Polar Programs, under grant DPP-8822027.

\section{REFERENCES}

Dahl-Jensen, D. and S.J. Johnsen. 1986. Palaeotemperatures still exist in the Greenland ice sheet. Nature, 320(6059), 250-252.

Hodge, S., D.L. Wright, J.A. Bradley, R.W. Jacobel, N. Skott, and B. Vaughn. In press. Determination of the surface and bed topography in Central Greenland. $J$. Glaciol.

Johnsen, S.J. 1977. Stable isotope profiles compared with temperature profiles in firn with historical temperature records. International Association of Hydrological Sciences Publication 118 (Symposium at Grenoble 1975 - Isotopes and Impurities in Snow and Ice), 388-392.

Paterson, W.S.B. 1981. The physics of glaciers. Second edition. Oxford, etc., Pergamon Press.

Sanderson, T.J.O. 1977. An error in ice-temperature measurement. J. Glaciol., 18(79), 329-333.

Weller, G. and P. Schwerdtfeger. 1977. Thermal properties and heat transfer processes of low-temperature snow. In Businger, J.A., ed. Meteorological studies at Plateau Station, Antarctica. Washington, DC, American Geophysical Union, 27-34. (Antarctic Research Series, 25.) 